\title{
Syntheses, characterization, and adsorption properties for metal ions of silica-gel functionalized by poly[8- methacroyloxy-quinoline]
}

\author{
I. Savchenko ${ }^{a}$, E. Yanovska ${ }^{a}$, L. Vretik ${ }^{a}$, D. Sternik ${ }^{b}$, and O. Kychkyruk ${ }^{c}$ \\ ${ }^{a}$ National Taras Shevchenko University of Kyiv, Kyiv, Ukraine; ${ }^{b}$ Maria Curie-Skłodowska University, Maria \\ Curie-Sklodowska Sq, Lublin, Poland; 'Ivan Franko Zhytomyr State University, Zhytomyr, Ukraine
}

\begin{abstract}
By mean of heterophase polymerization on the silica gel surface has been made in situ immobilization of poly [8-methacroyloxy-quinoline], has been received new organic-mineral composite material. Infrared and mass spectroscopy as well as termogravimetry (TG) analysis have been used to elucidate the structure of immobilized polymer. An adsorption capacity of the synthesized composite toward $\mathrm{Cu}(\mathrm{II}), \mathrm{Pb}(\mathrm{II}), \mathrm{Mn}(\mathrm{II}), \mathrm{Fe}(\mathrm{III}), \mathrm{Cd}(\mathrm{II})$ ions has been estimated. Adsorption activity to microquantities of $\mathrm{Cu}(\mathrm{II}), \mathrm{Mn}(\mathrm{II}), \mathrm{Fe}(\mathrm{III}), \mathrm{Cd}(\mathrm{II})$ in a neutral aqueous medium has been observed.
\end{abstract}

\section{KEYWORDS}

Adsorption; in situ immobilization; metal complexes; modified silica; poly [8-methacroyloxyquinoline

\section{Introduction}

Adsorbent materials are of great scientific and technological interest owing to their ability to interact with specific substances and efficiently separate them from a mixture. Owing to their superior physical and chemical features, including a large specific surface area, unique pore structure and tunable pore surface property, adsorbent materials have found utility in multiple applications, such as adsorption [1], separation/ purification [2], biosensors [3], drug delivery systems [4] and so on.

Silica based porous materials are considered as promising adsorbents for water remediation due to their high surface area, well-defined tunable pore size and high adsorption capacity. Owing to their economic feasibility, high thermal and mechanical stabilities, they can be utilized as inorganic solid matrixes in the inorganic-organic hybrid materials. Several researchers have contributed in the development of functionalized silica based adsorbents for the removal of heavy metals [5-7].

A large number of sorption methods have been proposed and used for the pre-concentration and removal of trace elements in the food and pharmaceutical industry, water purification, etc. With the purpose of concentrating and removing traces of metal species occurring in aqueous solutions several adsorbents have been studied, there are included activated carbon, polymers, ion exchangers, chelating resins and many others [8-10]. 
The modification of the surface of porous inorganic materials by nitrogen-containing polymers allows to obtain sorbents for removing toxic metals from the waste water due to their complexation with nitrogen atoms of immobilized polymer [11-13]. One of the promising ways of creating organo-mineral composite materials with valuable sorption properties is polymerization or in situ immobilization, which consists in the direct formation of an immobilized polymeric layer in the presence of particles of inorganic matrix [13-15].

This work is dedicated in situ immobilization of poly [8-methacroyloxy-quinoline] on the surface of silica gel, the study of surface morphology of modified silica gel and adsorption properties of the synthesized composite material on ions $\mathrm{Cu}(\mathrm{II}), \mathrm{Pb}(\mathrm{II})$, $\mathrm{Mn}(\mathrm{II}), \mathrm{Fe}(\mathrm{III}), \mathrm{Cd}(\mathrm{II})$.

\section{Experimental}

\subsection{Synthesis}

The synthesis of 8-methacroyloxy-quinoline is given below: 8-hydroxyquinoline $(18.15 \mathrm{~g}$, $.0125 \mathrm{~mol}$ ) was dissolved in $100 \mathrm{ml}$ anhydrous THF, and freshly distilled triethylamine $(34.78 \mathrm{ml}, 0.25 \mathrm{~mol})$ was added to the solution. The reaction mixture was then cooled to $0-5{ }^{\circ} \mathrm{C}$. Methacryloyl chloride $(24.41 \mathrm{ml}, 0.25 \mathrm{~mol})$ in THF $(50 \mathrm{ml})$ was injected gradually to the above solution via a glass syringe while the solution temperature was kept below $5{ }^{\circ} \mathrm{C}$. The reaction mixture was stirred overnight at room temperature. The resulting precipitate was filtered off. Purification was followed by recrystallization from methanol. Yield: $86 \%$.

\subsubsection{8-Methacroyloxy-quinoline}

${ }^{1} \mathrm{H}$ NMR (400 MHz, DMSO, $\left.\delta, \mathrm{ppm}\right): \delta 7.48-7.59$ (t, 3H), $8.85-7.85$ (s, 2H), 6.40 (s, $1 \mathrm{H} \mathrm{C}=\mathrm{CH}_{2}$, cis), 5.85 (s, $1 \mathrm{H} \mathrm{C}=\mathrm{CH}_{2}$, trans), 2.11 (s, $\left.3 \mathrm{H},=\mathrm{C}-\mathrm{CH}_{3}\right)$.

The polymerization of 8 -methacroyloxy-quinoline in the presence of silica gel (fraction of particles with a diameter of $0.1-0.2 \mathrm{~mm}$, specific surface $428.61 \mathrm{~m}^{2} / \mathrm{g}$, Merck) has been carried out under the argon atmosphere. A solution of $6.5 \mathrm{~g}$ 8-methacroyloxyquinoline and $0.065 \mathrm{~g}$ of $2,2^{\prime}$-azobisisobutyronitrile (AIBN) in $150 \mathrm{ml}$ tetrahydrofuran (THF) were poured into a flask containing $19.5 \mathrm{~g}$ of silica gel. When argon blowing was finished after $15 \mathrm{~min}$, the reaction mixture was heated to $78^{\circ} \mathrm{C}$; polymerization continued for $5 \mathrm{~h}$ with stirring. The reaction was stopped by cooling the reaction mixture. The resulting suspension was poured into a porcelain cup and left overnight to evaporate the solvent; the synthesized composite was washed three times with isopropyl alcohol, filtered and air-dried for $24 \mathrm{~h}$ at room temperature.

\subsection{Characterization methods}

IR spectra of the original and modified silica gel were recorded using an infrared spectrophotometer "Spectrum BX" (Perkin Elmer, Germany) in the range $500-4000 \mathrm{~cm}^{-1}$ in tablets $\mathrm{KBr}$. 
The amount of immobilized polymer on the silica gel surface was evaluated by thermogravimetric analysis results obtained with simultaneous TG/DTA analyzer Shimadzu DTG-60 H (Japan) with computer registration of data in the $15-1000{ }^{\circ} \mathrm{C}$ temperature range. The heating rate of samples is $10^{\circ} \mathrm{C} / \mathrm{min}$.

Thermal analysis was carried out on a STA 449 Jupiter F1, Netzsch (Germany) with mass spectroscopy console QMS 403 C Aeölos (Germany)

The values of the surface area, average volume and average pore diameter were calculated from the data of low temperature nitrogen adsorption/desorption isotherms using the "ASAP 2420 V1.01" (Micromeritics, USA) sorbetometric software. Before measurements, samples were degassed at $60^{\circ} \mathrm{C}$ for $24 \mathrm{~h}$.

The morphology of the surface of silica gel before and after modification by polymer was investigated by scanning electron microscopy using the electron microscope "SEM LEO 1430 VP" (Carl Zeiss, Germany).

Sorption characteristics of the synthesized material with respect to $\mathrm{Cu}$ (II), Cd (II), $\mathrm{Pb}$ (II) and Fe (III) ions were studied in static mode. At the same time, $0.1 \mathrm{~g}$ of the composite was contacted with $25-100 \mathrm{ml}$ of working solutions of nitrates of the corresponding metals. The interaction took place for 10, 30, 60, $90 \mathrm{~min}$ and day with mechanical shaking. The equilibrium concentration of metal ions was fixed by the atomic absorption method.

The working solutions of the nitrates of the selected metals for the study of the sorption properties of the modified silica gel were prepared from the sets of "standard samples of solutions" of these salts (produced by AV Bogatsky, Odessa) on the background of $1 \mathrm{MHNO}_{3}$ at concentrations of 1 and $10 \mathrm{mg} / \mathrm{ml}$.

To create a medium with $\mathrm{pH} 4$, a phthalate buffer solution was used from a set of "Standard buffer solutions" (DSTU 8.135: 2009, manufacturer of OJSC "Kiev plant of RIAP"). pH 2.8 was made by adding $0.1 \mathrm{M}$ acetic acid, which was prepared from fixanal. The exact $\mathrm{pH}$ of the working solutions was determined using the $\mathrm{pH}$ meter "HANNA TESTER WP" (Hanna instrument, China).

The adsorption capacity (A) was calculated using the formula:

$$
A=\left(c_{\mathrm{o}}-[M]\right) V / m
$$

where $c_{o}$ - initial molar metal concentration, $[M]$ - balanced molar metal concentration, $V$ - is the volume of the working solution, $m$ - is mass of the adsorbent (g).

The adsorption rate $(\mathrm{R})$ was calculated according to the equation:

$$
R=\left(m_{a d s} / m_{\mathrm{o}}\right) \cdot 100 \%=\left(m_{\mathrm{o}}-[m]\right) / m_{\mathrm{o}} \cdot 100
$$

where $m_{o}$ - is mass of metal in the starting solution $(\mathrm{mkg}), m_{\text {ads }}$ - is mass of the metal adsorbed, $[m]$ - is mass of the metal at equilibrium after the adsorption, which was found $[m]=\mathrm{C} \cdot V$, where $\mathrm{C}-$ is concentration of the metal at equilibrium $(\mathrm{mrg} / \mathrm{ml})$ and $V$ - is the volume of the solution at equilibrium $(\mathrm{ml})$.

The balanced metal ions concentration was defined by atom-absorption method. Atom-absorption measuring was made with the help flame atom-absorption spectrophotometer "Saturn" (Ukraine) in flame solution "air - propane - butane". The wavelengths were: for cuprum - $324.7 \mathrm{~nm}$, cadmium $-228.8 \mathrm{~nm}$, plumbum $-283.3 \mathrm{~nm}$, ferum $248.3 \mathrm{~nm}$, and the width of the crack of $0.58 \mathrm{~cm}$. The balanced concentrations calculations in solution were made by comparing method of their lines intensity in the 

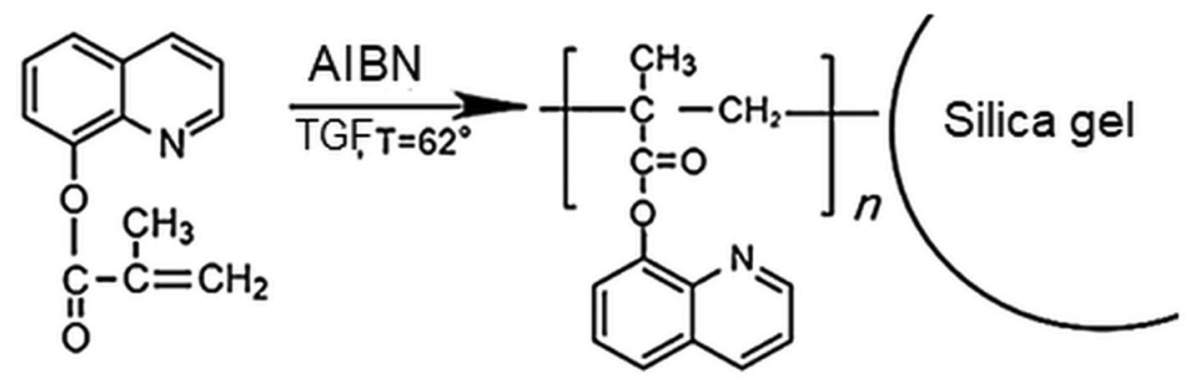

Figure 1. The scheme of in situ polymerization of 8-methacroyloxy-quinoline.

standard solutions intensity spector. Standard solutions were prepared with metal concentrations of $0.1-1.5 \mu \mathrm{g} / \mathrm{ml}$.

\section{Results and discussion}

The generalized scheme in situ immobilization of 8-methacroyloxy-quinoline on the silica gel surface is shown in Fig. 1.

The surface functionalization of silica gel with polymer was affirmed by FTIR spectroscopic analysis (Fig. 2). The bands at 1054 and $791 \mathrm{~cm}^{-1}$ are characteristic of asymmetric and symmetric vibrations of $\mathrm{Si}-\mathrm{O}-\mathrm{Si}$. The surface modification of polymer was confirmed by the appearance of stretching vibrations $v(\mathrm{C}-\mathrm{N})$ observed at $1580 \mathrm{~cm}^{-1}$. A number of bands at $1507,1474,1375 \mathrm{~cm}^{-1}$ can be attributed to the valence vibrations of the $\mathrm{C}-\mathrm{C}$ aromatic system [16]. The $\mathrm{C}=\mathrm{O}$ stretching vibration at $1680 \mathrm{~cm}^{-1}$ and further supported the immobilization of polymer on the surface of silica gel.

Thus, the results of IR spectroscopy confirm the presence of a polymer on the surface of silica gel.

In order to determine the concentration of immobilized polymer, a thermogravimetric analysis of the synthesized composite and the original silica gel was performed.

Figures 3 and 4 show the thermograms of the original silica gel and the synthesized composite.

The comparative analysis of the thermograms (Figs. 3 and 4) shows that the main loss of the composite mass due to the thermal decomposition of the immobilized polymer the loss of structured water in the composition of silica gel occurs in the range from 88 to $570{ }^{\circ} \mathrm{C}$. In this case, about $9.3 \%$ of the composite weight is lost. And the greatest mass losses are observed at temperatures from 388 to $515^{\circ} \mathrm{C}$. According to Fig. 4 the weight of water in the source silica gel is $5.4 \%$. Therefore, the mass of the immobilized polymer is $3.9 \%$.

In order to detail the process of thermodestruction of the composite, its thermogram, combined with mass spectrum, was obtained in 3D format (Fig. 5a), mass spectrum 2D format (Fig. 5b) and thermogram combined with infrared spectrum, in 3D format (Fig. 5c).

Mass spectral studies show that, as a result of thermal degradation of a polymer at temperatures above $400{ }^{\circ} \mathrm{C}$, particles with a mass of $1,82,628$ and $44 \mathrm{Da}$ are most likely formed, which most likely correspond to the formation of water, $\mathrm{CN}$-groups, ethine and $\mathrm{CO}_{2}$. In the temperature range of $200-400{ }^{\circ} \mathrm{C}$, the formation of a small number of 

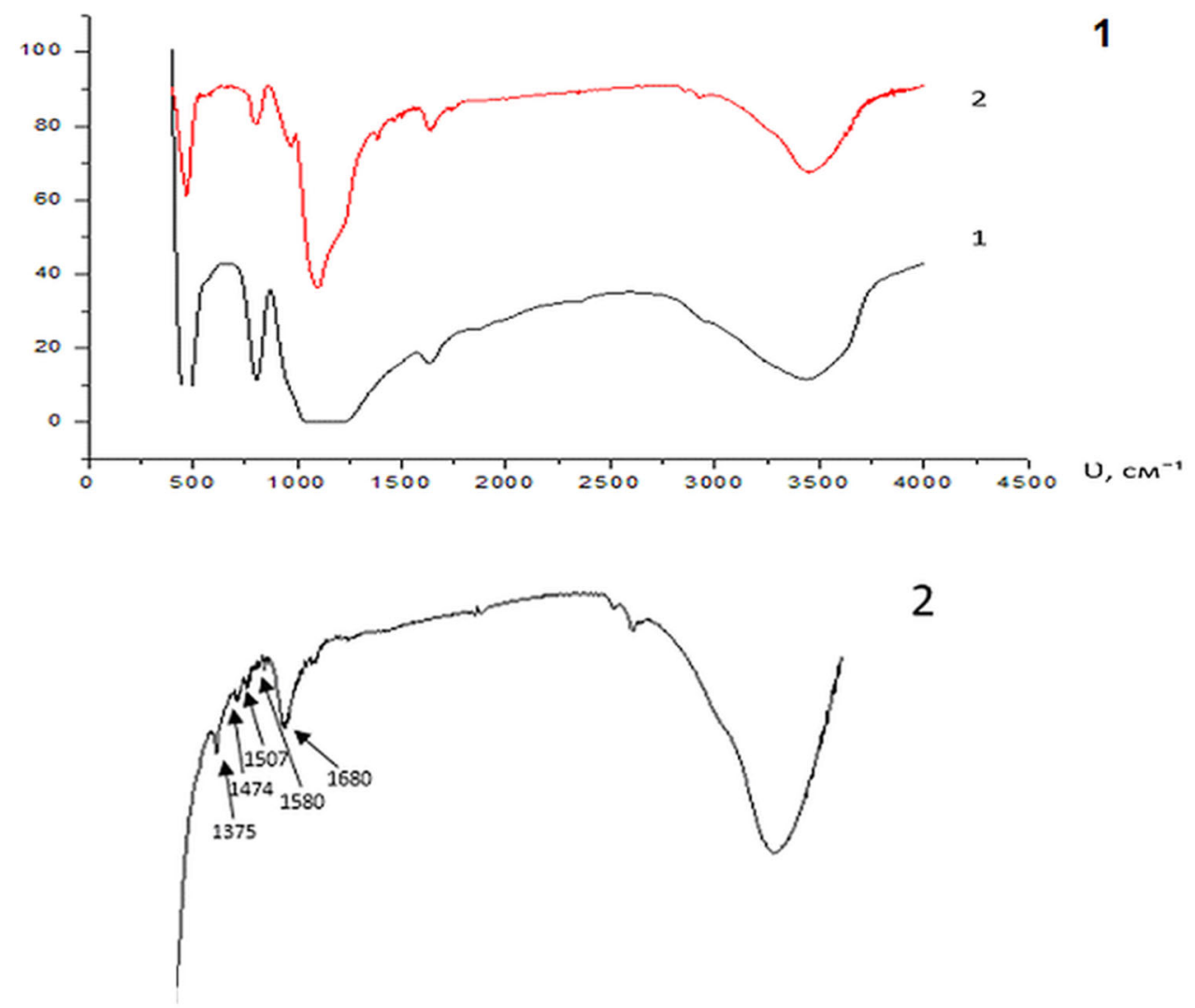

2

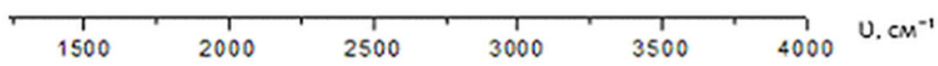

Figure 2. The FTIR-spectra of the original silica gel (1) and synthesized composite (2).

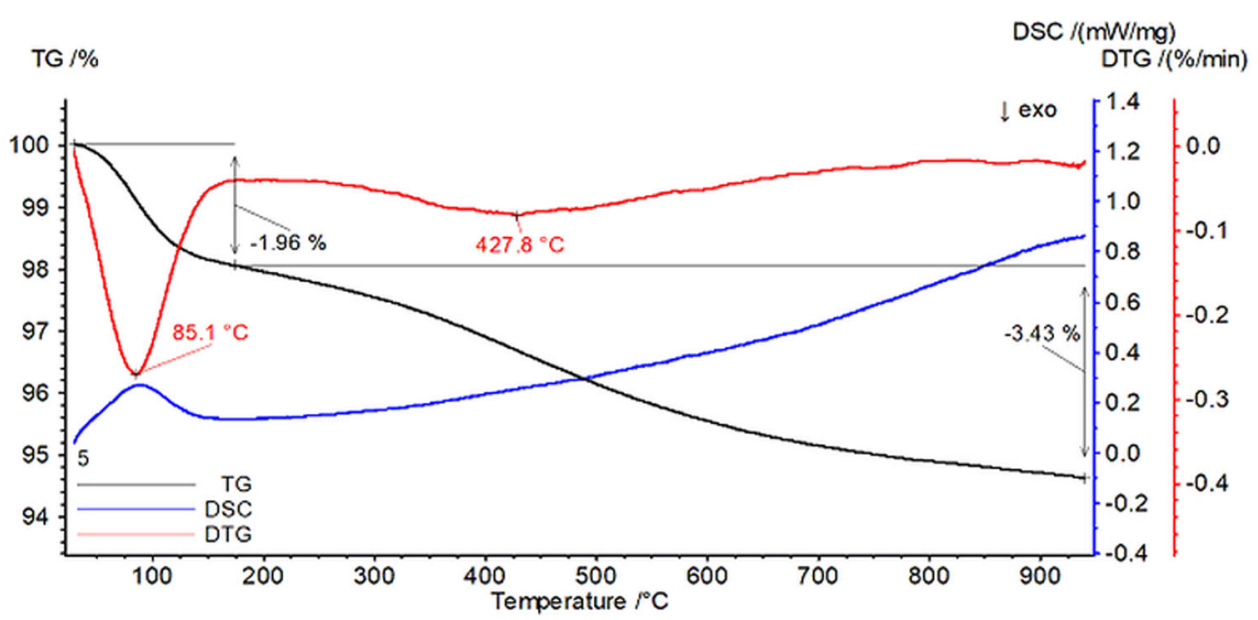

Figure 3. TG-, DTG-, DSC-curves of the silica gel. 


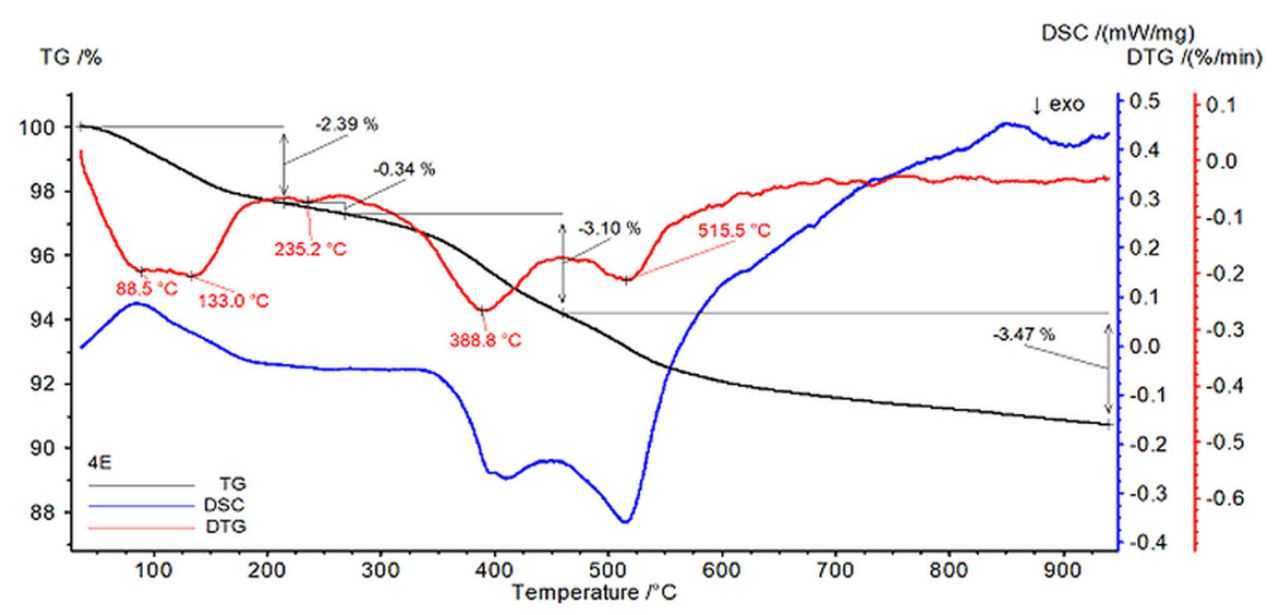

Figure 4. TG-, DTG-, DSC-curves of the synthesized composite.

particles with molecular masses 54 and 70, which most likely correspond to fragments of the carbon chain of a polymer.

To investigate the parameters of the surface of synthesized composites, the method of BET (low-temperature adsorption-desorption of nitrogen) was used. The resulting adsorption-desorption nitrogen isotherms for the original silica gel and the synthesized composite are similar and belong to the type IV isotherm according to the classification of IUPAC [17]. This suggests that the structure of the surface of silica gel as a result of fixing the polymer is unchanged practically.

The surface area, average volume, and pore size of the surface of the synthesized composite, calculated by computerized isotherm processing, are shown in Table 1 . The obtained data indicate that after the immobilization of the polymer, the surface area of the silica gel decreases slightly (from 447 to $389.7 \mathrm{~m}^{2} / \mathrm{g}$ ).

The mean pore volume decreases from 0.67 to $0.62 \mathrm{~cm}^{3} / \mathrm{g}$, and the average pore diameter increases from 5.92 to $6.08 \mathrm{~nm}$.

Changes in the surface morphology of silica gel after modification by polymer were followed by scanning electron microscopy (CEM). The CEM-photos of modified silica gel are shown in Figs. 6-8.

As can be seen from the above photos, the polymer is on the surface of silica gel in the form of balls and convex agglomerates due to its hydrophobicity, which do not affect the structure of silica gel.

Since the immobilized polymer is composed of 8-oxyquinoline groups, it must exhibit complex-forming activity with respect to transition metal ions due to nitrogen oxide. To confirm these considerations, we investigated the sorption of transition metal ions with a high affinity for nitrogen-containing ligands.

Investigation of the sorption capacity of the synthesized composite for these metal ions included:

- study of the rate of sorption of selected ions on the surface of the synthesized composite in static mode from aqueous nitrate solutions; 


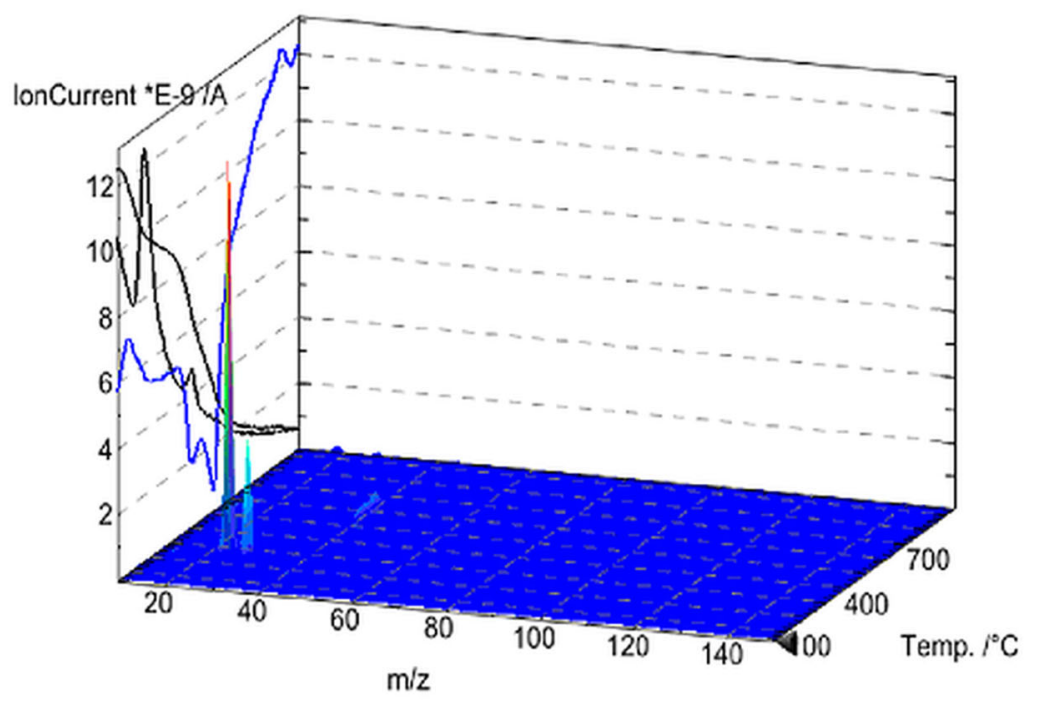

IonCurrent ${ }^{*} \mathrm{E}-9$ /A
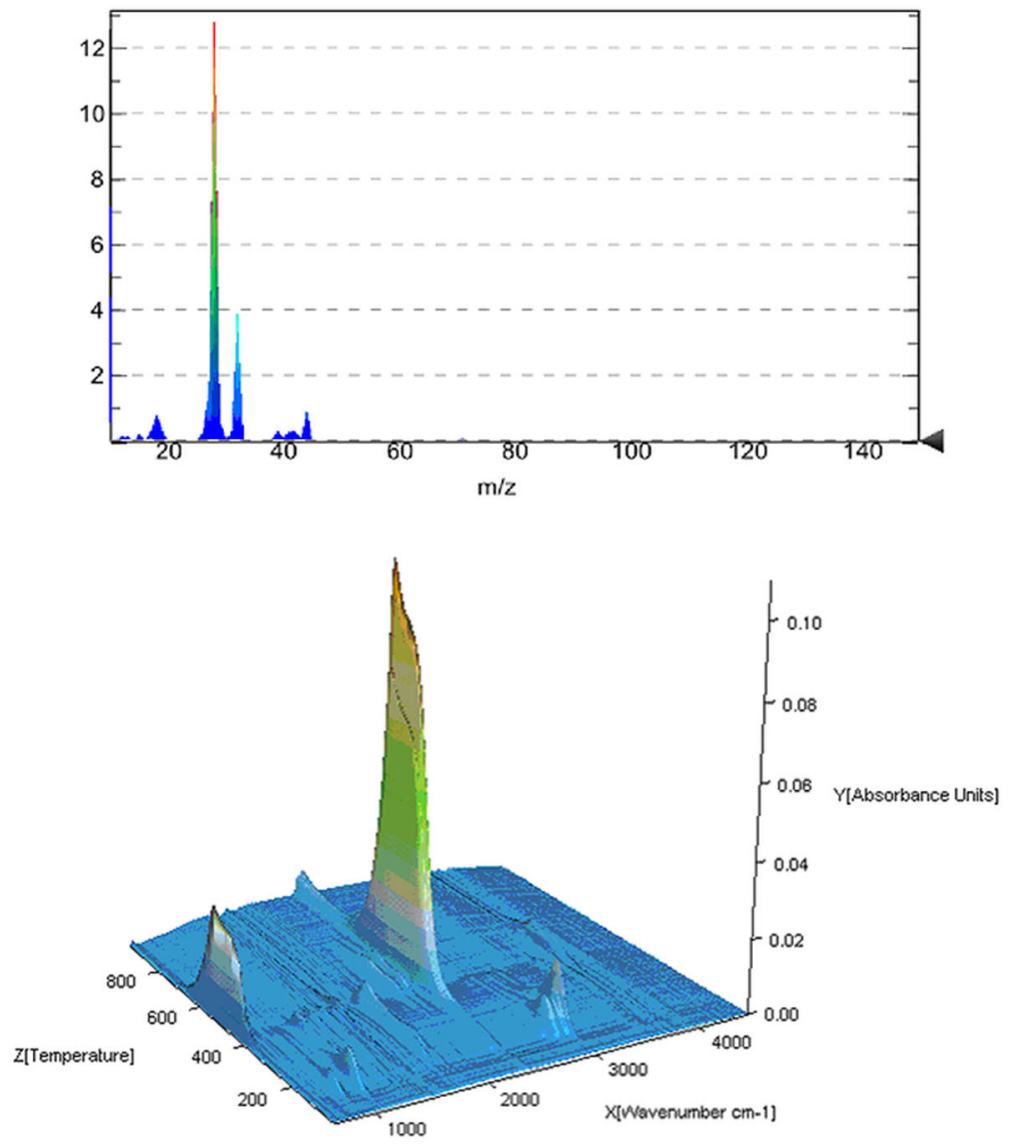

Figure 5. Mass spectrum DSC-QMS-3D (A), mass spectrum QMS-2D (B) and thermogram combined with infrared spectrum, in 3D format $(C)$ of the synthesized composite. 
Table 1. Characteristics of the surface of silica gel and synthesized composite.

\begin{tabular}{|c|c|c|c|c|c|}
\hline \multirow[b]{2}{*}{ Sample } & \multicolumn{3}{|c|}{ Surface area $\left(\mathrm{m}^{2} / \mathrm{g}\right)$} & \multirow[b]{2}{*}{ Average pore volume $(\mathrm{cm} 3 / \mathrm{g})$} & \multirow[b]{2}{*}{ Average pore size $(\mathrm{nm})$} \\
\hline & $P / P_{0}$ & BET & Langmuir & & \\
\hline Silica gel & 447.00 & 463.53 & 686.91 & 0.686 & 5.92 \\
\hline Composite & 389.70 & 407.31 & 609.77 & 0.619 & 6.08 \\
\hline
\end{tabular}

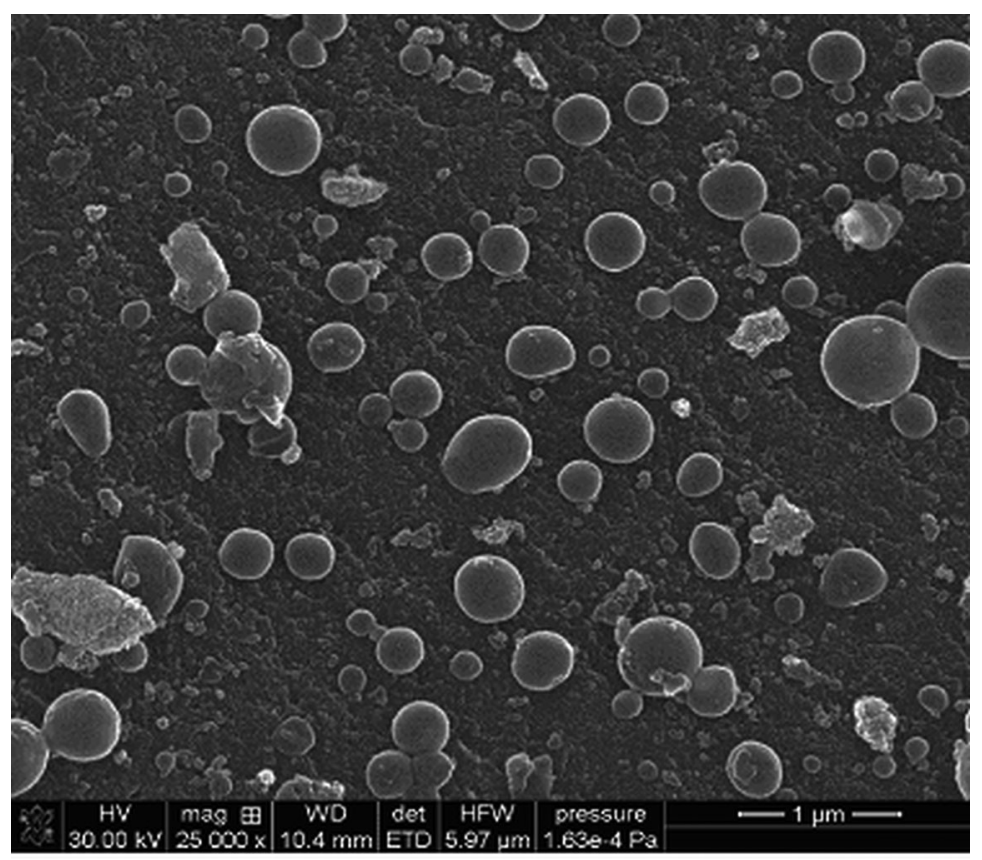

Figure 6. CEM photo of the surface of the composite at an increase of 25,000 times.

- construction of isotherms of sorption of each of the investigated metal ions on the surface of the synthesized composite;

- determination of sorption capacity for each of the investigated metal ions and comparison with the original silica gel.

The kinetics of sorption of selected metal ions by the composite surface is presented in Fig. 9.

The obtained data indicate that $\mathrm{Cu}(\mathrm{II})$ and $\mathrm{Pb}$ (II) ions are quantitatively adsorbed within the first ten minutes of contact with the composite surface. The Fe(III) and $\mathrm{Cd}(\mathrm{II})$ ions are maximally sorbed during the first minutes of contact. The degree of sorption of $\mathrm{Zn}$ (II) ions gradually increases over the course of an hour of contact, and then they are partially washed back into solution. $\mathrm{Mn}$ (II) ions are gradually sorbed during the first hour of contact, and completely washed back into solution within an hour. Based on the obtained data, the contact time of all metal ions with the surface of the composite during the experiments for the construction of sorption isotherms was one hour.

All the obtained isotherms (Figs. 10-14) belong to the 2L species, which indicates the uniform location of the sorbed metal ions on the surface of the composite. This 


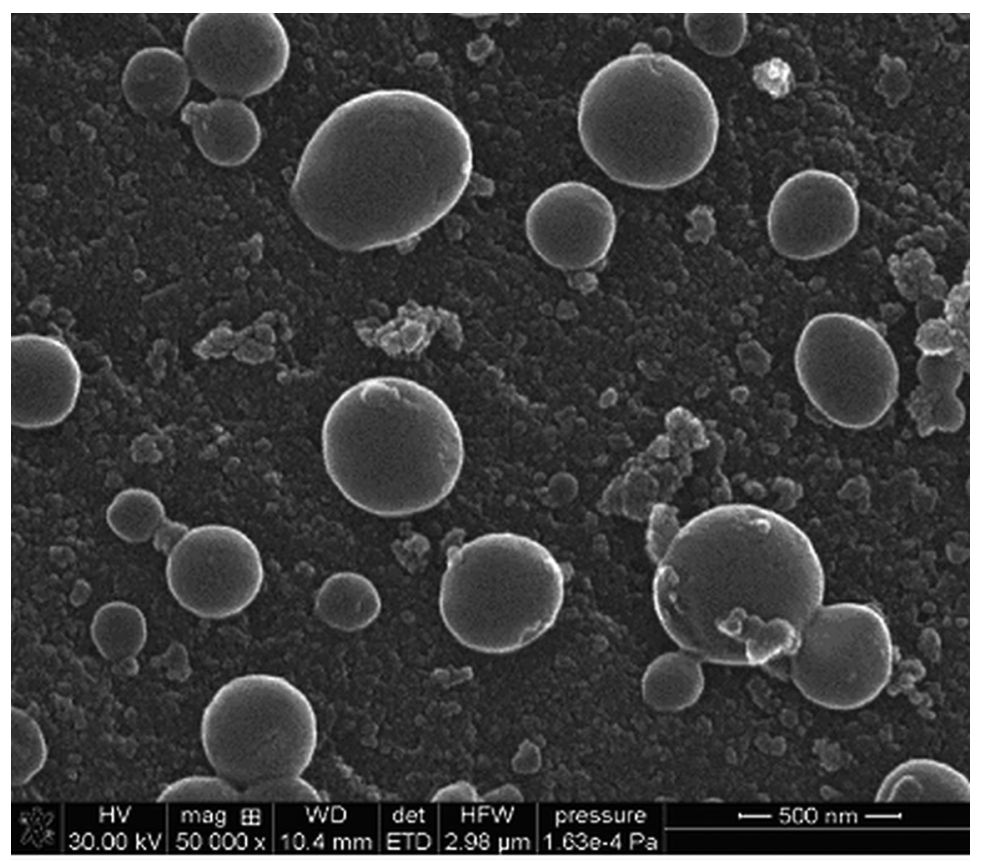

Figure 7. CEM photo of the surface of the composite at an increase of 50,000 times.

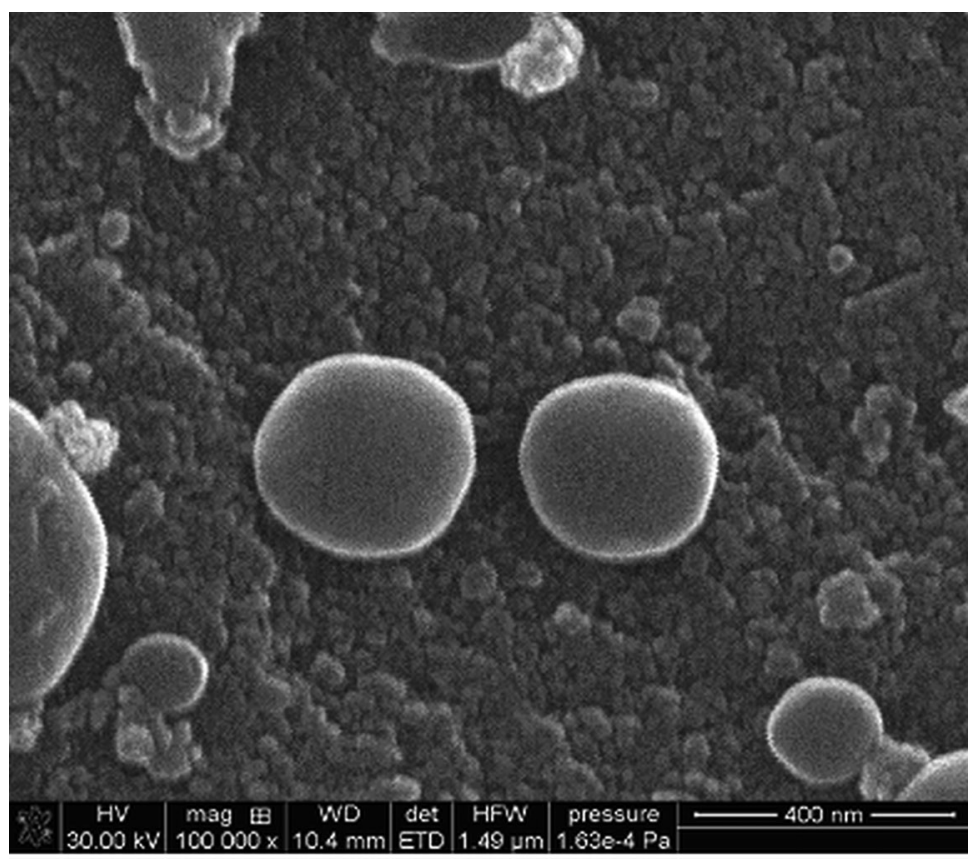

Figure 8. CEM photo of the surface of the composite at an increase of 1,00,000 times.

type of isotherms is typical of silica matrices modified by complexing substances. The obtained isotherms allow to calculate the sorption capacity of the synthesized composite. 


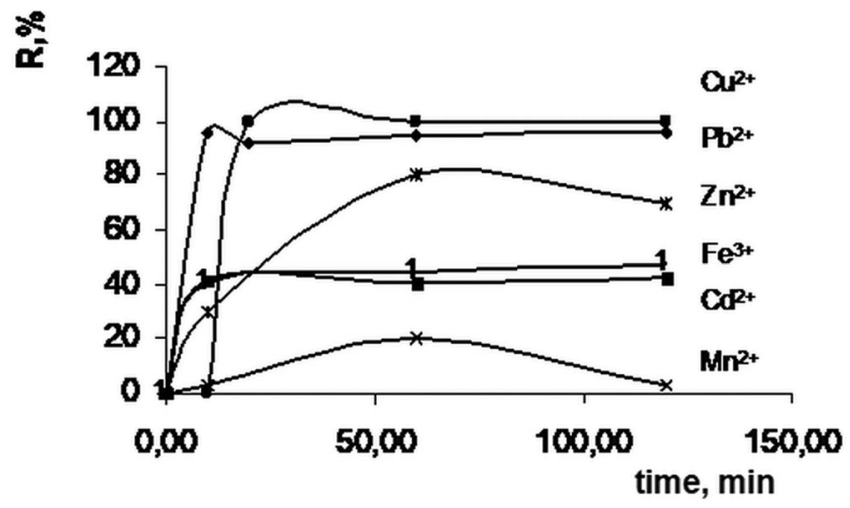

Figure 9. Kinetics of sorption of $\mathrm{Cu}^{2+}, \mathrm{Pb}^{2+}, \mathrm{Zn}^{2+}, \mathrm{Fe}^{3+}, \mathrm{Mn}^{2+}, \mathrm{Cd}^{2+}$ ions on the surface of silica gel, in situ modified poly [8-methacroyloxy-quinoline], in static sorption mode.

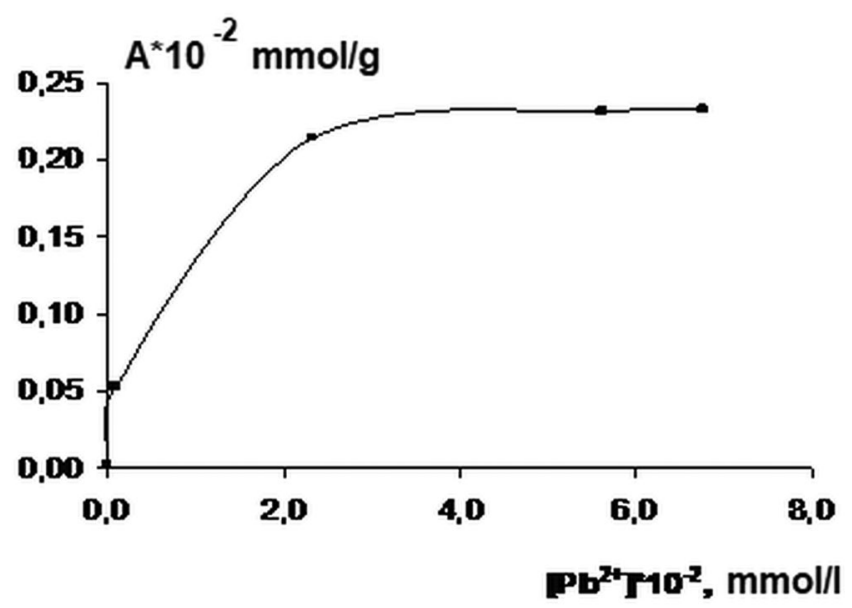

Figure 10. Adsorption isotherm of ions $\mathrm{Pb}$ (II) on silica gel with immobilized poly [8-methacroyloxy-quinoline].

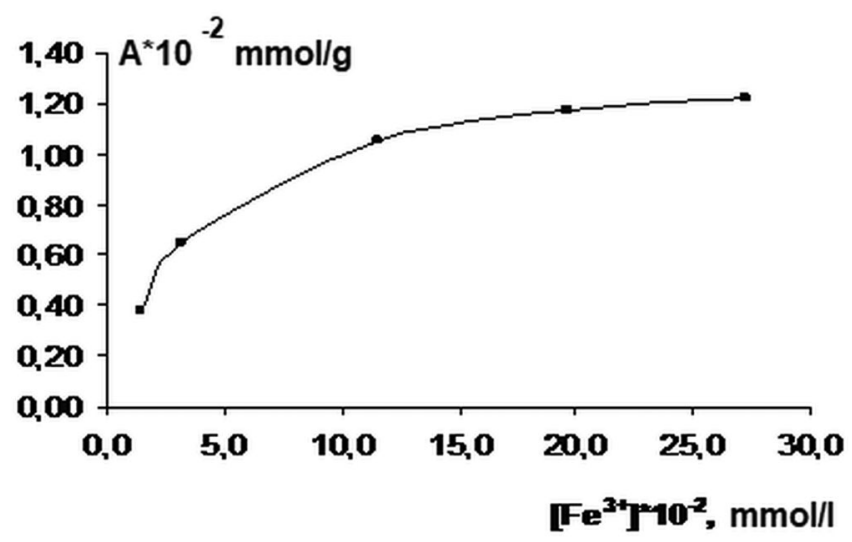

Figure 11. Adsorption isotherm of ions $\mathrm{Fe}(\mathrm{II})$ on silica gel with immobilized poly [8-methacroyloxy-quinoline]. 


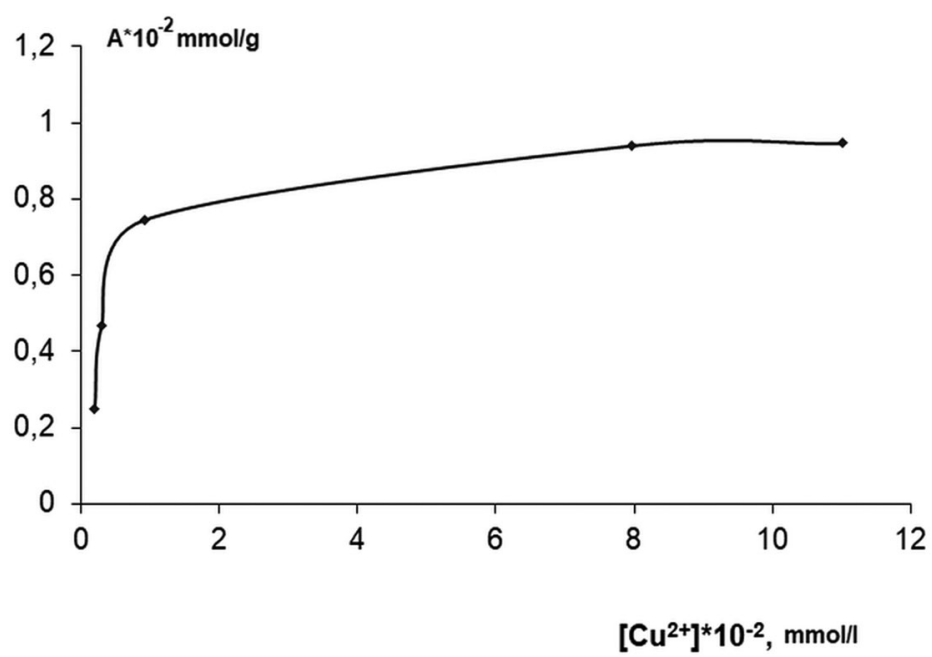

Figure 12. Adsorption isotherm of ions $\mathrm{Cu}(\mathrm{II})$ on silica gel with immobilized poly [8-methacroyloxy-quinoline].

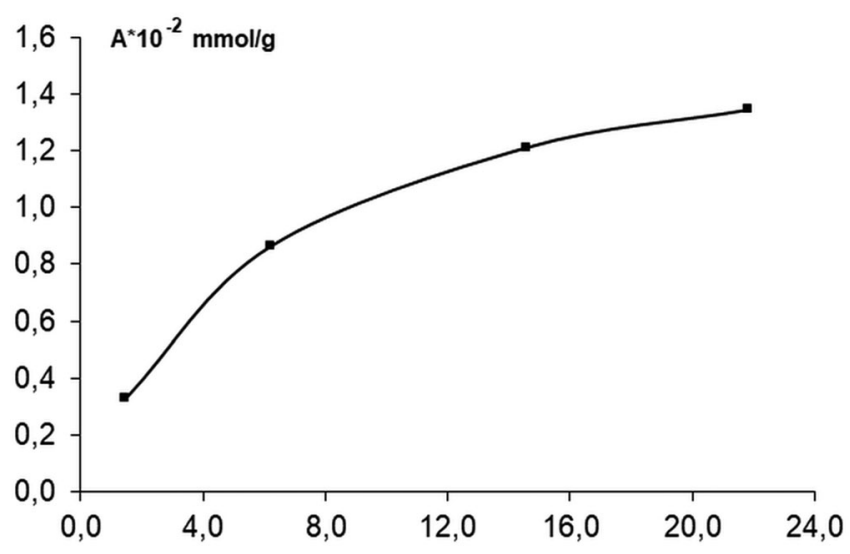

$\left[\mathrm{Mn}^{2+}\right]^{*} 10^{-2}, \mathrm{mmol} / \mathrm{l}$

Figure 13. Adsorption isotherm of ions $\mathrm{Mn}(\mathrm{II})$ on silica gel with immobilized poly [8-methacroyloxy-quinoline].

Comparison of the values of the sorption capacity of the synthesized composite with respect to $\mathrm{Cu}^{2+}, \mathrm{Pb}^{2+}, \mathrm{Zn}^{2+}, \mathrm{Fe}^{3+}, \mathrm{Mn}^{2+}, \mathrm{Cd}^{2+}$ ions found as a result of the processing of sorption isotherm data and the original silica gel (according to the literature) are shown in Table 2.

The data in this table suggest that the sorption capacity of silica gel after modification of poly [8-methacroyloxy-quinoline] with respect to $\mathrm{Cu}(\mathrm{II}), \mathrm{Fe}(\mathrm{III})$, and $\mathrm{Mn}$ (II) ions increases by approximately 1.5 times as a result of immobilization on the surface of the complexing polymer. But it remains unchanged with respect to $\mathrm{Pb}(\mathrm{II})$ ions. 


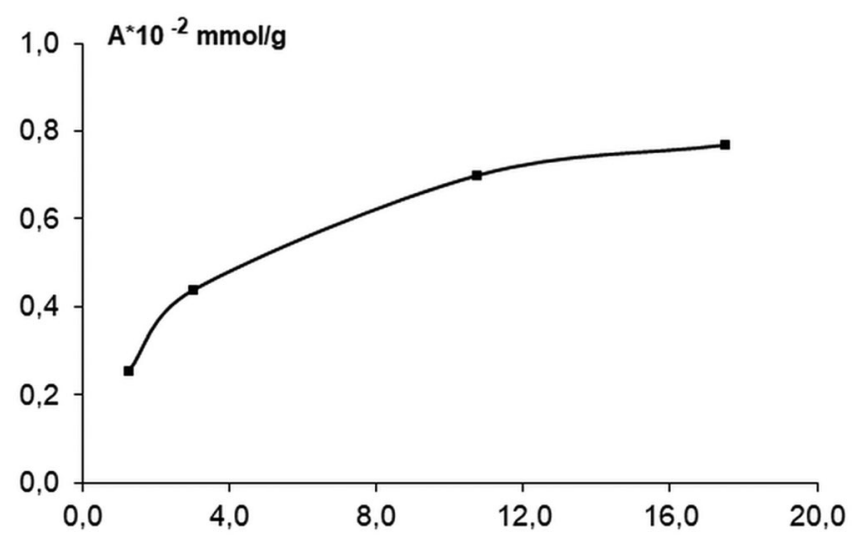

$\left[\mathrm{Cd}^{2+}\right]^{\star} 10^{-2}, \mathrm{mmol} / \mathrm{l}$

Figure 14. Adsorption isotherm of ions $\mathrm{Cd}(\mathrm{II})$ on silica gel with immobilized poly [8-methacroyloxy-quinoline].

Table 2. Adsorption capacity of the synthesized composite.

\begin{tabular}{lcccr}
\hline & \multicolumn{2}{c}{ Adsorption capacity } \\
\cline { 2 - 3 } & \multicolumn{2}{c}{ Original silica gel } & & Composite \\
\cline { 2 - 3 } \cline { 5 - 5 } Cation & $\mathrm{mmol} / \mathrm{g}$ & $\mathrm{mg} / \mathrm{g}$ & $\mathrm{mmol} / \mathrm{g}$ & $\mathrm{mg} / \mathrm{g}$ \\
\hline $\mathrm{Cu}(\mathrm{II})$ & 0.006 & 0.11 & 0.009 & 0.16 \\
$\mathrm{~Pb}(\mathrm{II})$ & 0.002 & 0.04 & 0.002 & 0.04 \\
$\mathrm{Fe}(\mathrm{III})$ & 0.008 & 0.14 & 0.012 & 0.22 \\
$\mathrm{Mn}(\mathrm{II})$ & 0.010 & 0.55 & 0.014 & 0.25 \\
$\mathrm{Cd}(\mathrm{II})$ & 0.06 & 0.67 & 0.008 & 0.14 \\
\hline
\end{tabular}

\section{Conclusions}

In summary, new organic composite material has been synthesized by in situ immobilization of poly [8-methacroyloxy-quinoline] on the surface of silica gel. Silica gel was functionalized with polymer to improve the adsorption behavior toward $\mathrm{Cu}^{2+}, \mathrm{Pb}^{2+}$, $\mathrm{Zn}^{2+}, \mathrm{Fe}^{3+}, \mathrm{Mn}^{2+}, \mathrm{Cd}^{2+}$ ions. The removal efficiency of polymer functionalized silica was compared with the original silica.

From the results of studies options after silica surface modified polymer by BET and according to scanning electron microscopy shows that immobilized polymer has no effect on the structure of the surface layer of silica gel practically.

The small increase in the sorption capacity of the synthesized composite with respect to the selected metal ions can be explained by the agglomerate arrangement of the immobilized polymer on the silica gel surface (Fig. 8) and, consequently, the steric inaccessibility of most complex metal centers for the metal ions.

The present study revealed that synthesized composite is promising materials for the removal of $\mathrm{Cu}(\mathrm{II}), \mathrm{Fe}(\mathrm{III})$, and $\mathrm{Mn}(\mathrm{II})$ ions from aqueous media 


\section{References}

[1] S. Nayab et al., RSC Adv. 8 (42), 23963 (2018). doi:10.1039/C8RA04209H

[2] H. Hongxing, G. Qiang, and F. Changgen, RSC Adv. 7, 15102 (2017).

[3] G. Fu, X. Yue, and Z. Dai, Biosens. Bioelectron. 26 (9), 3973 (2011). doi:10.1016/j.bios. 2011.03.007

[4] G. H. Gwak, S. M. Paek, and J. M. Oh, Eur. J. Inorg. Chem. 2012 (32), 5269 (2012). doi: 10.1002/ejic.201200583

[5] S. Babak, C. Chil-Hung, and W. Jiangning, Materials 7, 673 (2014).

[6] L. Hanyu et al., J. Mol. Liq. 273, 305 (2019).

[7] X. Zhijun et al., Separation and Purification Technology 191 (31), 61 (2018).

[8] E. Yanovska et al., Nanoscale Res. Lett. 12 (1), 313 (2017). doi:10.1186/s11671-017-2066-0

[9] H. Hong-Xing, G. Qiang, and F. Chang-Gen, Chin. J. Polym. Sci. 36 (4), 462 (2018).

[10] R. T. Déniz et al., Eclet. Quím. 32 (2), 13 (2007). doi:10.1590/S0100-46702007000200002

[11] A. D. Dadashev et al., Am. J. Anal. Chem. 07 (05), 411 (2016). doi:10.4236/ajac.2016. 75038

[12] I. Savchenko et al., Mol. Cryst. Liq. Cryst. 671 (1), 164 (2018). doi:10.1080/15421406.2018. 1542099

[13] Y. Polonska et al., Mol. Cryst. Liq. Cryst. 673 (1), 39 (2018). doi:10.1080/15421406.2019. 1578492

[14] V. Mittal, Materials 2 (3), 992 (2009). doi:10.3390/ma2030992

[15] K. V. Ryabchenko et al., Adsorption Sci. Technol. 32, 88 (2014).

[16] A. L. Smith, Applied IR Spectroscopy. Moscow: World (1982) (in Russian).

[17] G. D. Parfitt, Adsorption from Solution at the Solid Liquid Interface. Moscow: Mir (1986). 